\title{
Analisis Usaha Penangkapan Kepiting Bakau (Scylla sp.) Di Kelurahan Kandang, Kota Bengkulu
}

\section{Fishing Business Analysis of Mangrove Crab (Scylla sp.) In The Village Of Kandang, Bengkulu City}

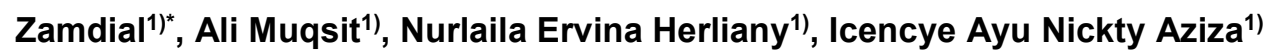 \\ 1) Program Studi IImu Kelautan, Universitas Bengkulu \\ *Penulis Korespondensi Email: zamdial et@yahoo.co.id \\ (Diterima September 2021/Disetujui Oktober 2021)
}

\begin{abstract}
The purpose of this study was to describe and analyze the feasibility of catching mangrove crabs (Scylla sp.) using a folding trap fishing gear in the waters of Kandang Village, Kampung Melayu District, Bengkulu City. This research was conducted for 1 month in September 2020. This research was using survey method. Research respondents consist of 13 fishermen mangrove crab in the waters of Kandang Village. The analysis method used descriptive method. The folding traps was used by fishermen have $45 \mathrm{~cm}$ long, $20 \mathrm{~cm}$ wide, and $15 \mathrm{~cm}$ high. The outboard motor boat was used by fishermen have 4,3 $\mathrm{m}$ long, 1,1 $\mathrm{m}$ wide, and 0,6 $\mathrm{m}$ high. The calculation of the gross tonnage of motor boat was 0,63 GT. The engines used were 5.5 PK-6.5 PK with engine brands including Honda, Nixon, Bion, Proquip and Pujiama. The mangrove crabs catch area in the waters of Kandang Village was around the waters of the mangrove forest with I sandy mud, and the distance was 2-3 $\mathrm{km}$ from the base fishing. The main catch of folding traps ismangrove crabs(Scylla sp.). The feasibility analysis of crab catch using folding traps in the waters of Kandang Village, Kampung Melayu District, Bengkulu City was declared feasible with the results of NPV was Rp. 2,097,872, Net B / C Ratio was 1.02, IRR was $27 \%$ using the level BRI Bank deposit interest rate was $12 \%$ and $P P$ was 2.61 years or 2 years 6 months 1 day.
\end{abstract}

Keywords: Trap, Fishing, Crab, Mangrove, Bengkulu

\begin{abstract}
ABSTRAK
Tujuan penelitian ini adalah mendeskripsikan dan menganalisis kelayakan usaha penangkapan kepiting bakau (Scylla sp.) dengan menggunakan alat tangkap bubu lipat di perairan Kelurahan Kandang, Kecamatan Kampung Melayu, Kota Bengkulu. Penelitian dilaksanakan selama 1 bulan pada bulan September 2020. Penelitian ini dilakukan dengan menggunakan metode survei. Responden penelitian terdiri dari 13 orang nelayan usaha penangkapan kepiting bakau yang menggunakan bubu lipat di perairan Kelurahan Kandang. Metode analisis data pada penelitian ini adalah metode deskriptif. Bubu lipat yang digunakan oleh nelayan berukuran panjang $45 \mathrm{~cm}$, lebar $20 \mathrm{~cm}$, dan tinggi $15 \mathrm{~cm}$. Perahu motor tempel yang digunakan nelayan berukuran panjang $4,3 \mathrm{~m}$, lebar 1,1 m, tinggi 0,6 m. Hasil perhitungan gross tonnage perahu motor tempel yaitu 0,63 GT. Mesin yang digunakan berkekuatan 5,5 PK - 6,5 PK dengan merek mesin diantaranya Honda, Nixon, Bion, Proquip dan Pujiama. Daerah penangkapan kepiting bakau di perairan Kelurahan Kandang berada di sekitar perairan hutan mangrove dengan dasar perairan berupa lumpur berpasir, dengan jarak dari base fishing yaitu 2-3 km. Hasil tangkapan utama bubu lipat adalah kepiting bakau (Scylla sp.). Analisis kelayakan usaha penangkapan kepiting bakau dengan menggunakan alat tangkap bubu lipat di perairan Kelurahan Kandang, Kecamatan Kampung Melayu, Kota Bengkulu dinyatakan layak dengan hasil NPV $=$ Rp 2.097.872, Net B/C Ratio $=1,02$, IRR $=27 \%$ menggunakan tingkat suku bunga deposito Bank $B R I 12 \%$ dan $P P=2,61$ tahun atau 2 tahun 6 bulan 1 hari.
\end{abstract}


Kata kunci :Bubu,Penangkapan, Kepiting, Mangrove, Bengkulu

\section{PENDAHULUAN}

Kota Bengkulu merupakan bagian dari Provinsi Bengkulu yang terletak di Pantai Barat Pulau Sumatera yang memiliki sumber daya hayati di sepanjang kawasan pesisir nya antara lain adalah ekosistem hutan mangrove, ekosistem hutan pantai, dan sumber daya perikanan. Kota Bengkulu memiliki sumber daya alam yang potensial untuk berbagai lapangan usaha perikanan baik perikanan darat maupun perikanan laut (Bappeda, 2017). Kelurahan Kandang yang terletak di Kecamatan Kampung Melayu, Kota Bengkulu memiliki ekosistem hutan mangrove yang menjadi lokasi nelayan untuk melakukan usaha penangkapan kepiting bakau. Penangkapan kepiting bakau oleh nelayan menggunakan bubu lipat, karena hasil tangkapan biasanya masih dalam keadaan hidup dan segar, serta bagian-bagian tubuh kepiting bakau masih lengkap, sehingga harga jualnya relatif mahal.

Bubu lipat merupakan alat tangkap pasif yang ramah lingkungan dan memiliki konsep pengoperasian yang mudah dengan menarik perhatian organisme menggunakan umpan, sehingga target dapat masuk dan terperangkap ke dalam bubu. Alat tangkap bubu termasuk alat tangkap ramah lingkungan karena bahan dari bubu sendiri aman untuk daerah perairan dan bahan bubu terdiri dari kawat dan jaring dimana kawat sebagai kerangkanya serta jaring sebagai alas penutup kerangkanya (Marliana et al, 2015). Daerah pengoperasian bubu lipat di perairan Kelurahan Kandang berada di ekosistem hutan mangrove, sehingga hasil tangkapan utama dari nelayan alat tangkap bubu lipat adalah kepiting bakau. Kepiting bakau merupakan salah satu komoditi perikanan yang memiliki nilai ekonomis penting dan digemari oleh masyarakat karena dagingnya yang enak dan nilai gizinya yang tinggi. Selain memiliki nilai ekonomis yang tinggi, kepiting bakau merupakan salah satu komoditas andalan untuk ekspor. Negara tujuan ekspor antara lain Amerika Serikat, Jepang, Australia, Benelux, Hongkong, Taiwan, Singapura, Korea Utara dan Korea Selatan (Kanna, 2002 dalam Rusdi, 2010).

Berdasarkan survei pendahuluan di perairan Kelurahan Kandang, Kecamatan Kampung Melayu, Kota Bengkulu, data dan informasi mengenai usaha penangkapan kepiting bakau (Scylla sp.) dengan menggunakan alat tangkap bubu lipat masih sangat minim. Tujuan penelitian ini untuk mendeskripsikan dan menganalisis kelayakan usaha penangkapan kepiting bakau (Scylla sp.) dengan menggunakan alat tangkap bubu lipat di perairan Kelurahan Kandang, Kecamatan Kampung Melayu, Kota Bengkulu. Hasil penelitian ini diharapkan dapat menjadi informasi dan acuan bagi nelayan dan stakeholder terkait deskripsi dan kelayakan usaha serta pengembangkan usaha penangkapan kepiting bakau (Scylla sp.) dengan menggunakan alat tangkap bubu lipat di perairan Kelurahan Kandang, Kecamatan Kampung Melayu, Kota Bengkulu.

\section{MATERIDAN METODE}

Penelitian ini dilaksanakan selama 1 bulan pada bulan September 2020 di Kelurahan Kandang, Kecamatan Kampung Melayu, Kota Bengkulu, yang merupakan musim penangkapan kepiting bakau oleh nelayan. Penelitian ini dilakukan dengan menggunakan metode survei. Data yang dikumpulkan adalah data primer dan data sekunder. Data primer diperoleh langsung dari lapangan melalui wawancara dan pengamatan secara langsung. Data primer terdiri dari unit penangkapan ikan (perahu/kapal penangkapan ikan), alat tangkap, daerah penangkapan dan operasi penangkapan kepiting bakau, pemasaran hasil tangkapan serta penanganan hasil tangkapan di atas perahu/kapal dan setelah didaratkan.Data sekunder meliputi semua data yang mendukung pembahasan dan penyusunan laporan hasil penelitian.

Responden penelitian adalah seluruh populasi nelayan yang memiliki unit penangkapan kepiting bakau yang menggunakan bubu lipat di Perairan Kelurahan Kandang, yaitu 13 orang.Dengan demikian penggunaan seluruh populasi tanpa harus menarik sampel penelitian sebagai unit observasi disebut sebagai teknik sensus (Sifa, 2017).

Metode analisis data adalah metode statistic deskriptif. Menurut Nasution (2009) dalam Purba (2018), metode deskriptif merupakan metode penelitian dengan cara mengumpulkan data sesuai dengan yang sebenarnya kemudian data tersebut disusun, diolah dan di analisis untuk dapat memberikan gambaran mengenai masalah yang ada.Analisa kelayakan usaha digunakan untuk melihat apakah usaha penangkapan kepiting bakau dengan menggunakan alat tangkap bubu lipat

To Cite this Paper: Zamdial., Muqsit, A., Herliany, N, E., Aziza, I, A, N., 2021. Analisis Usaha Penangkapan Kepiting Bakau (Scylla sp.) Di Kelurahan Kandang, Kota Bengkulu. Samakia: Jurnal Ilmu Perikanan, 12 (2): 147-159.

Journal Homepage: https://journal.ibrahimy.ac.id/index.php/JSAPI 
ini layak atau tidak untuk dijalankan secara berkelanjutan (Pratama et al., 2012). Menurut Shalichaty et al., (2014), metode analisis data menggunakan kriteria discounted dengan umur ekonomis proyek lebih dari 5 tahun, indikator yang digunakan adalah NPV (Net present Value), IRR (Internal Rate of Return), B/C Ratio, dan PP (Payback Period).

\section{Net Present Value (NPV)}

NPV yaitu selisih antara Present Value dari investasi dan nilai sekarang dari penerimaanpenerimaan kas bersih (arus kas operasional maupun arus kas terminal) di masa yang akan datang. Untuk menghitung nilai sekarang perlu ditentukan tingkat bunga yang relevan. Tingkat diskonto/discount factor (tingkat bunga $12 \% \mathrm{KCP}$ BRI). Rumus yang digunakan menurut Gray et al., (1992) adalah:

$$
N P V=\sum_{t=0}^{n} \frac{(B t-C t)}{(1+i)^{t}}
$$

\section{Dimana :}

$\mathrm{Bt}=$ Total benefit dari tahun $0,1, \ldots, \mathrm{n}$

$\mathrm{Ct}=$ Total biaya dari tahun $0,1, \ldots \ldots, \mathrm{n}$

$\mathrm{i}=$ Faktor diskonto (discount rate)

$\mathrm{t}=$ tahun operasi

$\mathrm{n}=$ umur kegiatan investasi

Pengambilan keputusan :

Apabila NPV > 0 maka usaha tersebut menguntungkan dan layak dijalankan, jika NPV $=0$ maka usaha tersebut layak tetapi tidak menguntungkan dan tidak merugikan, jika NPV $<0$ maka usaha tersebut tidak layak untuk dijalankan.

\section{Net Benefit-Cost Ratio (B/C Ratio)}

Net Benefit-Cost Ratio (B/C Ratio) adalah rasio antara manfaat bersih yang bernilai positif dengan manfaat bersih yang bernilai negatif (Gray et al., 1992), rumus yang digunakan :

(untuk $\mathrm{B}_{\mathrm{t}}-\mathrm{C}_{\mathrm{t}}>0$ )

(untuk $\mathrm{B}_{\mathrm{t}}-\mathrm{C}_{\mathrm{t}}<0$ )

Keterangan :

$$
\text { Net } B / C=\frac{\sum_{t=1}^{n} \frac{B t-C t}{(1+i)}}{\sum_{t=1}^{n} \frac{(t-B t}{(1+i)}}
$$

$\mathrm{B}_{\mathrm{t}}=$ total benefit dari tahun $0,1, \ldots, \mathrm{n}$

$\mathrm{C}_{\mathrm{t}}=$ Total biaya dari tahun $0,1, \ldots, \mathrm{n}$

$\mathrm{i}=$ discount rate

$\mathrm{n}=$ umur ekonomis usaha penangkapan ikan

Berdasarkan Net Benefit-Cost Ratio (B/C Ratio) suatu atau kegiatan investasi dapat dikatakan layak bila diperoleh Net $B / C \geq 1$ dan dikatakan tidak layak bila diperoleh Net $B / C \leq 1$.

\section{Internal Rate of Return (IRR)}

Kriteria Internal Rate of Return(IRR) untuk mengukur seberapa besar tingkat pengembalian proyek terhadap investasi yang ditanamkan ini dapat ditunjukkan dengan mengukur tingkat suku bunga (discount rate) yang menghasilkan NPV $=0$. Rumus yang digunakan untuk menghitung internal rate of returnmenurut Saebani (2018), adalah sebagai berikut:

Keterangan :

$$
I R R=\mathrm{i}_{1}+\frac{N P V_{1}}{N P V_{1}-N P V_{2}}\left(\mathrm{i}_{2}-\mathrm{i}_{1}\right)
$$

$\mathrm{i}_{1}=$ tingkat bunga yang disepakati (ke 1)

$\mathrm{i}_{2}=$ tingkat bunga sekarang (ke 2)

$N P V_{1}=N P V$ pada tingkat bunga ke $i_{1}$

$\mathrm{NPV}_{2}=\mathrm{NPV}$ pada tingkat bunga ke $\mathrm{i}_{2}$

\section{Payback Period (PP)}

Payback Period adalah jangka waktu yang diperlukan perusahaan untuk mengembalikan modal investasinya dari cash flow. Semakin cepat dana investasi dapat diperoleh kembali, semakin kecil risiko yang ditanggung oleh perusahaan. Selain itu, dana tersebut dapat digunakan untuk 
kebutuhan lain. Rumus yang digunakan untuk menghitung payback period menurut Saebani (2018), adalah sebagai berikut :

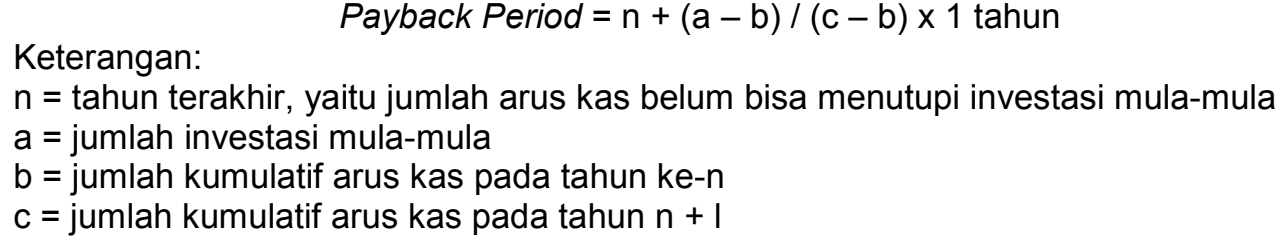

Setelah diketahui jangka waktu dari pengambilan investasi ini, selanjutnya dibandingkan dengan umur investasi untuk mengetahui layak atau tidaknya suatu investasi. Apabila payback period dari suatu investasi yang diusulkan lebih pendek daripada payback period maksimum, usul investasi tersebut dapat diterima. Sebaliknya, jika payback period lebih panjang daripada maksimumnya, usul investasi seharusnya ditolak

\section{HASIL DAN PEMBAHASAN}

\section{Gambaran Umum Lokasi Penelitian}

Kelurahan Kandang, Kecamatan Kampung Melayu, Kota Bengkulu memiliki luas wilayah yaitu 216 hektar, yang sebagian besar wilayah merupakan dataran rendah, tepi pantai/pesisir, dan kawasan rawa lebih kurang 40 hektar. Kelurahan Kandang merupakan kelurahan yang rentan terhadap bahaya bencana alam, karena berhadapan langsung dengan bibir pantai yang sewaktu-waktu dapat terjadi bahaya seperti tsunami, angin puting beliung, banjir, badai, abrasi dan sebagainya (Saraswati, 2014).

Kelurahan Kandang memiliki ekosistem hutan mangrove yang letaknya terpencar-pencar, tidak pada suatu hamparan yang luas. Kondisi ekosistem hutan mangrove ini sendiri sudah mengalami degradasi, karena sudah dimanfaatkan untuk berbagai kepentingan seperti pertambakan, pemukiman dan perluasan wilayah Kota Bengkulu. Untuk saat ini, keberadaan ekosistem hutan mangrove di Kelurahan Kandang tetap mempunyai fungsi dan peranan yang besar baik bagi masyarakat maupun sebagai daerah penyangga (Bappeda, 2017).

\section{Unit Penangkapan Bubu Lipat}

Bubu lipat diperairan Kelurahan Kandang dioperasikan oleh nelayan untuk menangkap kepiting bakau. Bubu lipat juga telah digunakan di perairan Kalimantan untuk menangkap kepiting bakau (Tiku, 2004) dan perairan Provinsi Jawa Barat serta Jawa Tengah untuk menangkap rajungan dan kepiting bakau (Iskandar, 2009; Setiawan, 2006; Muldiani, 2007; Lastari, 2007; Ramdani, 2007; Rusdi, 2010). Menurut Tallo (2015), kemudahan pengoperasian bubu lipat menyebabkan jenis bubu ini telah banyak tersebar di beberapa wilayah Indonesia dengan organisme target penangkapan adalah kepiting.

Secara umum konstruksi alat tangkap bubu lipat di perairan Kelurahan Kandang pada Gambar 1 sebagai berikut :

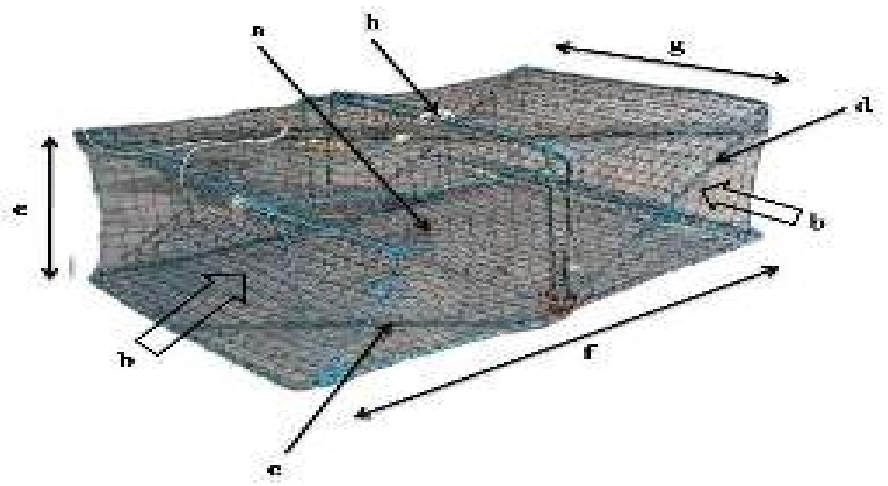

Gambar 1. Konstruksi Alat Tangkap Bubu Lipat (Dokumentasi penelitian, 2020)

Keterangan : a. Tempat umpan; b. Mulut bubu; c. Dinding; d. Rangka bubu; e. Tinggi bubu; f. Panjang bubu; g. Lebar bubu; h. Pengunci 


\section{Deskripsi Perahu/Kapal}

Perahu/kapal yang digunakan nelayan bubu lipat di perairan Kelurahan Kandang Kota Bengkulu mempunyai ukuran rata-rata panjang 4,3 meter, lebar 1,1 meter, dan tinggi 0,6 meter, terbuat dari bahan kayu. Perahu/kapal berukuran 0,63 GT.Perahu/kapal yang digunakan termasuk kelompok perahu motor tempel yang berukuran kecil. Penelitian Rusdi (2010), kapal yang digunakan dalam pengoperasian bubu lipat memiliki dimensi $L \times B \times D: 3 \times 1 \times 20 \mathrm{~cm}$, terbuat dari kayu. Kapal dilengkapi dayung yang berfungsi untuk mengatur posisi kapal pada saat pemasangan bubu. Menurut Sumali et al.,(2012), kapal perikanan pada umumnya menggunakan bahan utama kayu, karena kayu sebagai material yang relatif murah dan mudah dalam pengerjaan bila dibandingkan kapal baja dan kapal fiber.

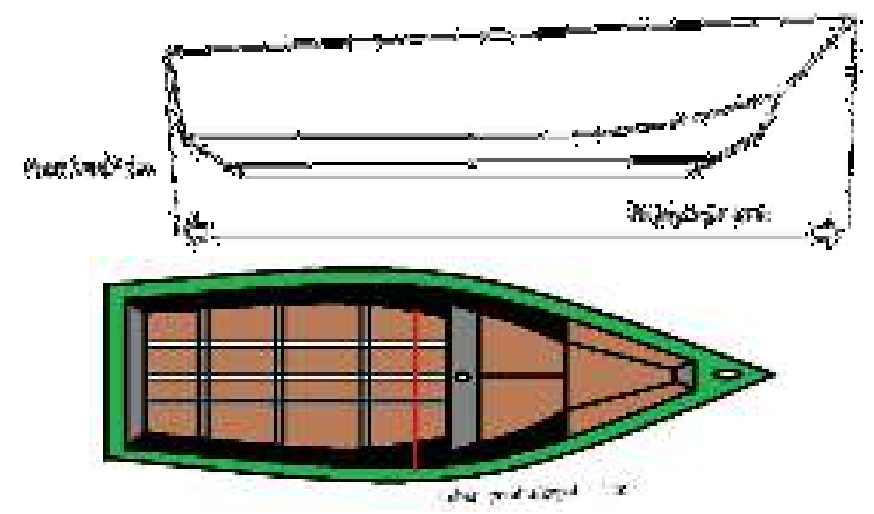

Gambar 2. Desain perahu/kapal bubu lipat dari samping (kiri) dan desain perahu/kapal bubu lipat dari atas (kanan) di perairan Kelurahan Kandang Kecamatan Kampung Melayu Kota Bengkulu

(Dokumentasi penelitian, 2020)

\section{Mesin Perahu/Kapal}

Mesin penggerak perahu motor tempel yang digunakan oleh nelayan untuk penangkapan kepiting bakau dengan bubu lipat di perairan Kelurahan Kandang Kota Bengkulu adalah mesin motor tempel berkekuatan5,5 - 6,5 PK dengan merek Honda, Nixon, Bion, Proquip dan Pujiama. Berdasarkan penelitian Rusdi (2010), kapal penangkapan kepiting bakau yang menggunakan alat tangkap bubu lipat di Kabupaten Subang, Desa Mayangan menggunakan mesin dengan merk Honda berkekuatan 5 PK. Mesin sebagai penggerak perahu yang digunakan nelayan kelurahan Kandang dapat dilihat pada Gambar 3.

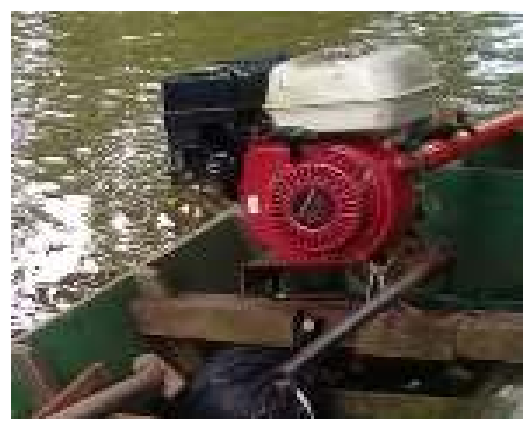

Gambar 3. Mesin perahu/kapal bubu lipat (Dokumentasi penelitian, 2020)

\section{Nelayan dan Anak Buah Kapal (ABK)}

Operasi penangkapan kepiting bakau dengan bubu lipat di perairan Kelurahan Kandang yang menggunakan perahu motor tempel berukuran kecil, hanya bisa memuat satu orang nelayan dan alat tangkap bubu lipat yang akan dioperasikan.Menurut Rusdi (2010), nelayan yang mengoperasikan bubu lipat pada penangkapan kepiting bakau di Kabupaten Subang termasuk ke dalam nelayan kecil. Jumlah nelayan yang mengoperasikan bubu lipat ini berjumlah 2 orang. Pembagian tugas dalam pengoperasian bubu lipat tersebut adalah satu orang sebagai juru mudi dan satu orang lainnya bertugas dalam pengoperasian bubu lipat (setting-hauling).

To Cite this Paper: Zamdial., Muqsit, A., Herliany, N, E., Aziza, I, A, N., 2021. Analisis Usaha Penangkapan Kepiting Bakau (Scylla sp.) Di Kelurahan Kandang, Kota Bengkulu. Samakia: Jurnal Ilmu Perikanan, 12 (2): 147-159.

Journal Homepage: https://journal.ibrahimy.ac.id/index.php/JSAPI 


\section{Metode dan Daerah Penangkapan Kepiting Bakau}

Metode penangkapan kepiting bakau menggunakan alat tangkap bubu lipat oleh nelayan Kelurahan Kandang, Kota Bengkulu dilakukan satu trip per hari (one day trip fishing).Pemasangan bubu oleh nelayan di perairan Kelurahan Kandang adalah dengan sistem tunggal. Sistem tunggal juga dilakukan di Dobo Kabupaten Kepulauan Riau Provinsi Maluku untuk penangkapan kepiting bakau menggunakan alat tangkap bubu lipat (Ediyanto dan Gutandjal, 2015).

Pengoperasian alat tangkap bubu lipat di perairan Kelurahan Kandang terdiri atas beberapa tahap. Tahap pertama persiapan,yaitu sebelum melakukan penangkapan, nelayan bubu lipat melakukan pengecekan alat tangkap yang sudah terpasang umpan dan menyusunnya di dalam perahu, pengecekan dan pengisian bahan bakar terhadap mesin perahu, pengecekan keamanan perahu yang akan digunakan dan mempersiapkan perbekalan kedalam perahu.Tahap kedua,melakukan perjalanan selama \pm 1 jam untuk mencari daerah penangkapan/fishing ground yang umumnya telah dikenal dan diketahui oleh para nelayan diperairan Kelurahan Kandangdi sekitar ekosistem hutang mangrove.Tahap ketiga, melakukan pemasangan bubu di perairan dimulai dari penurunan bubu yang telah diberi umpan dan diakhiri oleh pelampung tanda. Dalam setiap trip nelayan biasanya memasang bubu sebanyak 25-50 unit. Jarak pemasangan antar bubu yaitu $\pm 10 \mathrm{~m}$ dengan kedalaman 2-3 m. Pada penelitian Ediyanto dan Gutandjal (2014), kedalaman 1-5 m untuk pemasangan bubu lipat pada penangkapan kepiting bakau di Provinsi Maluku. Pada penelitian Shalicaty et al., (2014), untuk operasi penangkapan rajungan dengan alat tangkap bubu lipat di perairan Tegal, jarak antara 1 bubu dengan bubu lainnya berkisar 5 meter hingga 7 meter.Lama waktu bubu dipasang dalam air, tergantung kondisi pasang surut. Bubu dapat dipasang selama 5-6 jam. Selama bubu di pasang,nelayan mengambil kesempatan untuk beristirahat sejenak sembari memantau bubu dari perahu untuk mengetahui kapan melakukan pengangkatan (hauling). Beberapa nelayan ada yang memilih untuk kembali ke pangkalan untuk beristirahat. Tahap hauling atau pengangkatan bubu dilakukan dengan urutan berkebalikan dengan tahap setting, yaitu dimulai dari pengangkatan pelampung tanda dan diakhiri oleh pengangkatan bubu.

Daerah penangkapan kepiting bakau di perairan Kelurahan Kandang sesuai dengan tangkapan utama berupa kepiting bakau berada di sekitar hutan mangrove, dengan dasar perairan berupa lumpur berpasir. Sama seperti penelitian Muldiani (2007), bahwa daerah penangkapan bubu adalah perairan yang mempunyai dasar perairan berlumpur maupun pasir ataupun daerah berkarang tergantung ikan yang menjadi tujuan penangkapan. Daerah penangkapan kepiting bakau di perairan Kelurahan Kandang yaitu berjarak 2-3 km dari pangkalan.

Aktivitas penangkapan kepiting bakau oleh nelayan bubu lipat di perairan Kelurahan Kandang biasanya dilakukan bersamaan saat pasang sedang naik. Menurut Rangka (2007), biasanya operasi penangkapan bersamaan pasang naik pada waktu kepiting aktif mencari makan. Rakhmadevi (2014), juga menjelaskan bahwa kepiting bakau mengikuti pola pasang surut harian dimana kepiting akan mencari makan pada saat pasang dan akan kembali ke tempat persembunyiannya pada saat perairan mulai surut.

\section{Hasil Tangkapan}

Rata-rata hasil tangkapan kepiting bakau tertinggi yang didapatkan nelayan bubu lipat di perairan Kelurahan Kandang adalah sebanyak $5 \mathrm{~kg}$ per trip, sedangkan rata-rata hasil tangkapan kepiting bakau paling sedikit adalah sebanyak $2 \mathrm{~kg}$ per trip bahkan terkadang pernah tidak mendapatkan hasil tangkapan. Hasil tangkapan sampingan (bycatch) yang didapatkan berupa udang-udangan dan ikan gabus (Channa striata) dan tidak banyak, sehingga hanya untuk dikonsumsi oleh nelayan saja. Menurut Irnawati et al., (2014), hasil tangkapan bubu lipat selama penelitian di perairan Lontar Kabupaten Serang Banten berjumlah 2.594 ekor yang terdiri atas 12 jenis. Hasil tangkapan utama berupa kepiting bakau (Scylla serrata) sebanyak 307 ekor (11\%), diikuti dengan hasil tangkapan sampingan ekonomis tinggi berupa rajungan (Portunus pelagicus) 47 ekor, keong macan (Babylonia spirata) sebanyak 521 ekor dan jenis tangkapan lainnya yang termasuk ikan ekonomis rendah.

Pada penangkapan kepiting bakau menggunakan bubu lipat di Kelurahan Kandang, jenis umpan yang digunakan berupa ikan rucah jenis ikan selengek (Alepes melanoptera), ikan gulama (Johnius trachycephalus), ikan maco (Leiognathus sp), ikan seriding (Ambassis nalua), ikan 
belanak (Mugil cephalus) dan kepala ayam. Pada penelitian Tiku (2004), penangkapan kepiting bakau dengan bubu lipat menggunakan umpan daging ikan remang, ikan rucah dan kelapa bakar.

\section{Penanganan dan Pengolahan Hasil Tangkapan}

Penanganan hasil tangkapan di atas perahu/kapal bubu lipat di perairan Kelurahan Kandang dilakukan dengan cara meletakan langsung hasil tangkapan kepiting bakau ke dalam ember plastik yang sudah disiapkan. Sebelum diletakkan kedalam ember, kepiting terlebih dahulu diikat menggunakan tali rafia yang sudah disiapkan agar saat dipegang aman dari capitan nya dan mudah ditangani saat penimbangan di darat. Pada saat di darat, kepiting bakau diletakkan di wadah yang lebih besar untuk mengurangi resiko kematian karena stres. Kepiting bakau bisa bertahan selama 2-3 hari dengan bantuan air laut yang sesekali sedikit disiramkan ke dalam wadah tersebut. Menurut Rangka (2007), hasil penangkapan segera dilakukan pengikatan sehingga mudah penanganan selanjutnya. Sebaiknya hasil tangkapan yang telah diikat jangan disimpan terlalu lama (lebih dari 3 hari) agar mutu tidak menurun.

Hasil tangkapan kepiting bakau dengan menggunakan bubu lipat di perairan Kelurahan Kandang Kota Bengkulu tidak ada yang diolah karena hasil tangkapan langsung dijual.

\section{Pemasaran Hasil Tangkapan}

Kepiting bakau hasil tangkapan nelayan di perairan Kelurahan Kandang, Kota Bengkulu, dijual langsung kepada konsumen. Pada saat sampai di darat, hasil tangkapan kepiting langsung dibawa ke pengepul untuk dijual dan beberapa nelayan memilih menjual sendiri kepiting bakau kepada konsumen. Alasan nelayan menjual langsung hasil tangkapan mereka, karena harga jual kepiting bakau ke pengepul masih terbilang lebih murah dibandingkan menjual langsung kepada konsumen.

Rantai pemasaran hasil tangkapan kepiting bakau menggunakan bubu lipat di perairan Kelurahan Kandang, Kecamatan Kampung Melayu, Kota Bengkulu dapat dilihat pada Gambar 4 berikut ini :

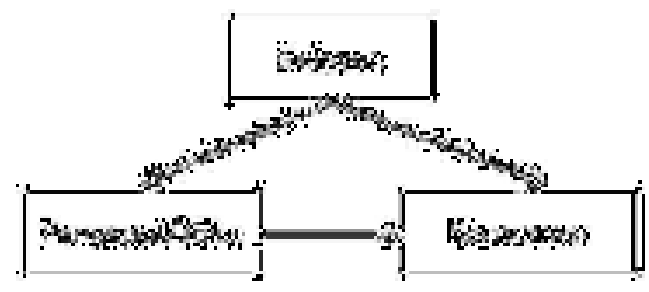

Gambar 4. Rantai pemasaran hasil tangkapan kepiting bakau menggunakan bubu lipat di perairan Kelurahan Kandang, Kecamatan Kampung Melayu, Kota Bengkulu

Menurut Ediyanto dan Gutandjal (2015), sistem pemasaran kepiting bakau (Scylla serrata) di Dobo menggunakan dua saluran, yaitu saluran pertama; nelayan menjual kepada pedagang besar.Dari pedagang besar, setelah penyortiran dan pengepakan, langsung didistribusikan ke pedagang pengencer.Saluran kedua, kepiting bakau dari nelayan dijual kepada para agen penunjang, lalu dijual kepada pedagang besar yang berada di Dobo, untuk didistribusikan kepada pedagang pengencer yang ada di Jakarta.

Hasil tangkapan yang diperoleh nelayan beragam ukuran. Biasanya nelayan dan pedagang pengepul di Kelurahan Kandang, Kota Bengkulu menghargai kepiting bakau berdasarkan bobotnya.Untuk bobot kepiting bakau 1,5-1,9 ons dihargai dengan harga $25.000 / \mathrm{kg}$, bobot kepiting bakau $>2$ ons dihargai dengan harga $50.000 / \mathrm{kg}$ dan untuk bobot kepiting bakau $>3$ ons dihargai dengan harga $100.000 / \mathrm{kg}$. Menurut Saidah dan Sofia (2016), harga rata-rata kepiting bakau di pasaran berkisar Rp 40.000 - Rp 200.000 per kg. Namun, pemenuhan permintaan kepiting bakau sebagian besar $( \pm 61,6 \%)$ masih dari penangkapan alam, sedangkan dari budidaya hanya sebagian kecil $( \pm 38,4 \%)$.

\section{Analisis Aspek Finansial}

\section{A. Biaya Investasi}

Komponen biaya investasi usaha penangkapan kepiting bakau dengan bubu lipat oleh nelayan di Kelurahan kandang, Kota Bengkulu, dapat dilihat pada Tabel 1. 
Tabel 1. Komponen biaya investasi rata-rata yang dikeluarkan tahun pertama untuk penangkapan kepiting bakau dengan bubu lipat di perairan Kelurahan Kandang, Kecamatan Kampung Melayu Kota Bengkulu

\begin{tabular}{llllr}
\hline No & \multicolumn{1}{c}{ Biaya Investasi } & \multicolumn{1}{c}{ Umur Teknis } & & Rata-rata \\
\hline 1. & Perahu Motor Tempel & 2,7 Tahun & Rp. & 1.653 .846 \\
2. & Alat Tangkap Bubu Lipat & 1 Tahun & Rp. & 1.451 .538 \\
3. & Mesin & 9,3 Tahun & Rp. & 2.346 .154 \\
4. & Lampu (senter) & 11,1 Bulan & Rp. & 87.308 \\
\hline \multicolumn{2}{l}{ JUMLAH } & Rp. & $\mathbf{5 . 5 3 8 . 8 4 6}$ \\
\hline
\end{tabular}

Sumber : Analisa Data Primer (2020)

Berdasarkan hasil wawancara, diketahui bahwa harga setiap unit dari satu pemilik usaha penangkapan berbeda dengan pemilik usaha lainnya. Hal ini disebabkan oleh beberapa faktor, diantaranya terdapat nelayan yang membeli satu set perahu/kapal yang sudah siap pakai dan ada juga nelayan yang membuat sendiri perahu/kapal tersebut sehingga biaya yang dikeluarkan pun lebih murah. Selain itu, tiap tahun terjadi kenaikan harga dari masing-masing unit usaha penangkapan tersebut.

Pada Tabel 1dapat diketahui semua komponen biaya investasi pada usaha penangkapan kepiting bakau dengan bubu lipat di perairan Kelurahan Kandang, Kecamatan Kampung Melayu, Kota Bengkulu, yaitu perahu motor tempel, dengan umur teknis rata-rata 2,7 tahun, alat tangkap bubu lipat dengan umur teknis rata-rata 12 bulan, mesin perahu motor tempel dengan umur teknis ratarata 9,3 tahun, dan lampu (senter) dengan umur teknis rata-rata 11,1 bulan. Total biaya investasi yang dikeluarkan pada tahun pertama adalah sebesar Rp. 5.538.846.

Menurut penelitian Tilaar (2019), pada analisis pendapatan nelayan penangkapan kepiting bakau di Kecamatan Singkil dan Kecamatan Kuala Baru,biaya investasi yang dikeluarkan meliputi sampan dengan harga rata-rata sebesar Rp. 1.037.500. Dayung dengan harga rata-rata sebesar Rp. 40.000. Bubu dengan harga untuk satu unit penangkapan sebesar Rp. 1.425.000. Keranjang dengan harga rata-rata sebesar Rp. 42.000.

B. Biaya Tetap

Komponen biaya tetap pada usaha penangkapan kepiting bakau dengan bubu lipat di perairan Kelurahan Kandang, Kecamatan Kampung Melayu, Kota Bengkulutahun 2020 meliputi biaya penyusutan dan perawatan peralatan nelayan yang digunakan dalam melakukan aktivitas penangkapan seperti perahu, alat tangkap, mesin perahu dan lampu (senter) seperti yang disajikan pada Tabel 2.

Tabel 2. Biaya tetap perawatan rata-rata dan penyusutan rata-rata di perairan Kelurahan Kandang, Kecamatan Kampung Melayu Kota Bengkulu

\begin{tabular}{clcc}
\hline No & \multicolumn{1}{c}{ Biaya Tetap } & \multicolumn{2}{c}{ Rata-rata/Unit/Tahun } \\
\hline 1 & Perawatan Perahu & Rp. & 437.349 \\
2 & Perawatan Alat Tangkap Bubu Lipat & Rp. & 99.692 \\
3 & Perawatan Mesin & Rp. & 231.538 \\
4 & Perawatan Lampu (senter) & Rp. & 750.000 \\
5 & Penyusutan Perahu & Rp. & 640.513 \\
6 & Penyusutan Alat Tangkap Bubu Lipat & Rp. & 1.451 .538 \\
7 & Penyusutan Mesin & Rp. & 255.385 \\
8 & Penyusutan Lampu & Rp. & 77.885 \\
\hline \multicolumn{2}{c}{ JUMLAH } & Rp. & $\mathbf{3 . 9 4 3 . 9 0 0}$ \\
\hline
\end{tabular}

Sumber : Analisa Data Primer (2020)

Pada Tabel 2 dapat diketahui, bahwa biaya perawatan terbesar adalah lampu (senter).Hal ini dikarenakan beberapa nelayan menggunakan lampu (senter) dengan harga murah dengan umur ekonomis rendah, sehingga mudah rusak.Ada 1-2 nelayan yang menggunakan lampu (senter) dengan masih memakai baterai sehingga baterai tersebut harus diganti tiga hari sekali dengan biaya $\pm R p 2.500$, yang jika ditotalkan dalam setahun biaya rata-rata perawatan lampu (senter) bisa mencapai Rp 750.000 pertahunnya.

Pada perawatan perahu, mesin dan alat tangkap bubu lipat tidak banyak perbedaan. Jika ada perbedaan, hal tersebut karena jenis perbaikan dan kerusakan yang berbeda-beda untuk tiap

To Cite this Paper: Zamdial., Muqsit, A., Herliany, N, E., Aziza, I, A, N., 2021. Analisis Usaha Penangkapan Kepiting Bakau (Scylla sp.) Di Kelurahan Kandang, Kota Bengkulu. Samakia: Jurnal Ilmu Perikanan, 12 (2): 147-159.

Journal Homepage: https://journal.ibrahimy.ac.id/index.php/JSAPI 
faktor produksi. Misalnya biaya pergantian oli pada mesin dengan biaya rata-rata mencapai Rp 231.538. Biaya rata-rata perawatan perahu/kapal mencapai Rp 437.349, yaitu pengecatan dan perbaikan perahu yang bocor.Biaya rata-rata perawatan alat tangkap bubu lipat mencapai Rp 99.692, yaitu membeli benang untuk perbaikan jaring bubu yang putus. Tabel 2 menunjukan jika semua penyusutan pada unit penangkapan yang dioperasikan harus dihitung dan diketahui, total dari biaya tetap per tahun sebesar Rp 3.943.900.

Menurut Mufriantie et al., (2019), bahwa biaya tetap yang dikeluarkan pada usaha penangkapan kepiting bakau di Desa Pasar Ngalam Kecamatan Air Periukan Kabupaten Seluma meliputi biaya penyusutan alat-alat seperti sampan, bubu, senter, parang, sepatu, cuban, karung dan tali troll. Biaya tetap yang dikeluarkan sebesar Rp. 82.311,40/bulan. Selanjutnya Tilaar (2019) juga menjelaskan, bahwa biaya tetap yang dikeluarkan pada analisis pendapatan nelayan penangkapan kepiting bakau di Kecamatan Singkil dan Kecamatan Kuala Baru meliputi biaya penyusutan alat-alat seperti sampan, dayung, bubu dan keranjang. Biaya tetap yang dikeluarkan sebesar Rp. 141.125/bulan.

\section{Biaya Tidak Tetap/Operasional}

Biaya tidak tetap pada operasi penangkapan kepiting bakau di perairan Kelurahan Kandang terdiri dari biaya perbekalan dapat dilihat pada Tabel 3.

Tabel 3. Biaya tidak tetap/operasional rata-rata penangkapan bubu lipat dalam tahun $2020 \mathrm{di}$ perairan Kelurahan Kandang, Kecamatan Kampung Melayu Kota Bengkulu

\begin{tabular}{|c|c|c|c|}
\hline No & Komponen & Rata-rata/Trip & Rata-rata/Tahun \\
\hline 1. & Perbekalan & 65.477 & Rp. $\quad 18.860 .677$ \\
\hline
\end{tabular}

Dalam satu tahun melaut nelayan penangkapan kepiting bakau dengan menggunakan alat tangkap bubu lipat di perairan Kelurahan Kandang (untuk 295 trip), total biaya operasional mencapai $\mathrm{Rp}$ 18.860.677. Biaya perbekalan yang dimaksud sudah meliputi biaya bahan bakar mesin (bensin). Bensin yang digunakan 1-2 liter dalam satu trip melaut, konsumsi, rokok, dan umpan yang digunakan sebanyak $3 \mathrm{~kg}$ dalam satu trip.

Menurut Mufriantie et al., (2019), biaya variabel yang dikeluarkan pada usaha penangkapan kepiting bakau di Desa Pasar Ngalam Kecamatan Air Periukan Kabupaten Seluma meliputi biaya tenaga kerja dan biaya operasional yang dikeluarkan setiap proses kegiatan produksi meliputi umpan, tali rafia, baterai, rokok, garam, autan dan bensin. Biaya operasional yang dikeluarkan sebesar Rp. 340.719,11 dan biaya tenaga kerja yang dikeluarkan sebesar Rp. 570.476,97. Jadi jumlah biaya variabel sebesar Rp. 911.196,08/bulan.Artinya jumlah biaya variabel dalam usaha pencari kepiting bakau cukup besar yang akan mengurangi pendapatan bagi nelayan. Untuk meningkatan pendapatan dalam usaha penangakapan kepiting bakau, maka yang perlu diperhatikan adalah mengurangi biaya, terutama pada biaya operasional sehingga dapat mengurangi jumlah biaya variabel yang cukup besar.

\section{Hasil Pendapatan}

Hasil pendapatan nelayan penangkapan kepiting bakau dengan menggunakan alat tangkap bubu lipat di perairan Kelurahan Kandang Kecamatan Kampung Melayu Kota Bengkulu 2020 dapat dilihat pada Tabel 4.

Tabel 4.Hasil pendapatan rata-rata alat tangkap bubu lipat di perairan Kelurahan Kandang Kecamatan Kampung Melayu Kota Bengkulu 2020

\begin{tabular}{llcl}
\hline No & Hasil Tangkapan & Rata-rata/Bulan & \multicolumn{2}{c}{ Rata-rata/Tahun } \\
\hline 1. & Kepiting Bakau & Rp. 2.076 .923 & Rp. 24.923 .077 \\
\hline Sumber : Analisis Data Primer (2020) & &
\end{tabular}

Sumber : Analisis Data Primer (2020)

Jumlah hasil tangkapan usaha penangkapan kepiting bakau oleh nelayan di perairan Kelurahan Kandang Kota Bengkulu adalah sebanyak 1.240,6 kg dengan nilai pendapatan Rp 24.923.077, untuk operasi penangkapan 295 trip dalam setahun.Sebagai perbandingan, hasil penelitian Amarullah et al., (2018) mendapatkan, bahwa setiap nelayan mempunyai rata-rata jumlah produksi kepiting bakau setiap tahunnya yaitu sekitar $689,23 \mathrm{~kg} / \mathrm{tahun}$. Usaha nelayan kepiting bakau

To Cite this Paper: Zamdial., Muqsit, A., Herliany, N, E., Aziza, I, A, N., 2021. Analisis Usaha Penangkapan Kepiting Bakau (Scylla sp.) Di Kelurahan Kandang, Kota Bengkulu. Samakia: Jurnal IImu Perikanan, 12 (2): 147-159. 
menggunakan bubu di Kecamatan Samatiga Kabupaten Aceh barat memperoleh pendapatan sebesar Rp. 34.461.818/tahun.

Pada Tabel 5 berikut ini dapat dilihat hasil analisis 4 kriteria investasi usaha penangkapan kepiting bakau dengan menggunakan alat tangkap bubu lipat di Kelurahan Kandang, Kecamatan Kampung Melayu, Kota Bengkulu pada Tahun 2020.

Tabel 5. Analisis Finansial penangkapan kepiting bakau menggunakan alat tangkap bubu lipat di perairan Kelurahan Kandang Kecamatan Kampung Melayu Kota Bengkulu

\begin{tabular}{|c|c|c|c|}
\hline Komponen & Nilai & Indikator & Keterangan \\
\hline NPV & $\begin{array}{ll}\operatorname{Rp} & 2.097 .872\end{array}$ & $>0$ & Layak \\
\hline Net B/C Ratio & 1,02 & $>1$ & Layak \\
\hline IRR & $27 \%$ & $>12 \%$ & Layak \\
\hline Payback Period & 2,61 & $<5$ Tahun & Layak \\
\hline
\end{tabular}

Sumber : Analisa Data Primer (2020)

\section{NPV (Net Present Value)}

Pada Tabel 5 dapat diketahui, bahwa nilai NPV(Net Present Value)usaha penangkapan kepiting bakau menggunakan bubu lipat di perairan Kelurahan Kandang Kota Bengkulu, dengan suku bunga deposito bank BRI sebesar $12 \%$ adalah Rp. 2.097.872. Nilai tersebut menunjukkan bahwa pada akhir usaha penangkapan kepiting bakau menggunakan bubu lipat, terdapat keuntungan sebesar Rp. 2.097.872. Nilai NPV pada usaha penangkapan kepiting bakau dengan menggunakan bubu lipat bernilai positif, yang berarti bahwa usaha penangkapan kepiting bakau dengan menggunakan bubu lipat ini menguntungkan dan layak untuk dijalankan

Menurut Gray et al., (1992) NPV menunjukan manfaat bersih yang diterima dari suatu usaha selama umur usaha menguntungkan dan layak dijalankan. Jika NPV $>0$ maka usaha tersebut menguntungkan dan layak dijalankan, jika NPV $=0$ maka usaha tersebut tidak menguntungkan dan tidak mengalami kerugian, jika NPV $<0$ maka usaha tersebut tidak menguntungkan dan mengalami kerugian sehingga tidak layak dijalankan.

Menurut Husnan dan Muhammad (2005) dalam Shalichatyet al., (2014), apabila nilai sekarang penerimaan-penerimaan kas bersih dimasa yang akan datang lebih besar daripada nilai sekarang investasi, maka proyek ini dikatakan menguntungkan sehingga diterima. Sedangkan apabila lebih kecil (NPV negatif), proyek ditolak karena dinilai tidak menguntungkan. Bila NPV $>0$ berarti investasi usaha perikanan tangkap tersebut layak, sehingga menjadi pertimbangan positif untuk pengembangannya. Dari hasil tersebut usaha dikatakan menguntungkan kerena nilai NPV lebih dari 0 atau bernilai positif.

\section{Net B/C (Net Benefit - Cost Ratio)}

Menurut Gray et al., (1992), Benefit Cost Ratio ( B/C Ratio) suatu proyek kegiatan investasi dapat dikatakan layak bila diperoleh Net B/C Ratio > 1 dan dikatakan tidak layak bila diperoleh Net B/C Ratio $<1$, jika Net B/C Ratio = 1 maka usaha suatu proyek tersebut berada pada kondisi Break Even Point (BEP). Nilai B/C ratio usaha penangkapan kepiting bakau menggunakan bubu lipat di perairan Kelurahan Kandang Kota Bengkulu adalah sebesar 1,02 yang berartikan lebih $>1$. Dan usaha layak untuk dilanjutkan. Menurut Rahardi dan Hartono (2003) dalamShalichatyet al., (2014), suatu usaha dikatakan layak dan memberikan manfaat apabila nilai B/C Ratio lebih besar dari nol. Semakin besar nilai B/C Ratio maka semakin besar nilai manfaat yang akan diperoleh dari usaha tersebut. Besar B/C ratio yang didapatkan lebih besar dari 0 maka usaha tersebut dikatakan feasible atau layak untuk dijalankan.

\section{IRR (Internal Rate of Return)}

Menurut Wismaningrum et al., (2013), apabila hasil perhitungan IRR lebih besar dari discount factor maka dikatakan usaha tersebut layak untuk diteruskan, bila samadengan discount factor berarti pulang pokok dan di bawah discount factor makaproyek tersebut tidak dapat diteruskan. Sama seperti Saebani (2018), menyatakan jika IRR lebih besar (>) dari suku bunga yang diterapkan, investasi diterima. Jika IRR lebih kecil $(<)$ dari suku bunga yang diterapkan, investasi ditolak. 
Internal Rate of Return usaha penangkapan kepiting bakau menggunakan bubu lipat di perairan Kelurahan Kandang Kota Bengkulu adalah sebesar 27\%. Nilai IRR tersebut lebih besar dariDiscount factor yang digunakan (12\%). Hal tersebut menunjukkan bahwa usaha penangkapan kepiting bakau menggunakan bubu lipat di perairan Kelurahan Kandang Kota Bengkulu dikatakan layak dan menguntungkan.

\section{PP (Payback Period)}

Payback period (PP)rata-rata usaha penangkapan kepiting bakau menggunakan bubu lipat di perairan Kelurahan Kandang, Kota Bengkulu adalah 2,61 tahun atau 2 tahun 6 bulan 1 hari. Jangka waktu PP yang didapatkan, memperlihatkan indikasi investasi usaha tersebut layak untuk dilakukan.Payback period merupakan metode yang digunakan untuk mengukur seberapa cepat suatu investasi dapat kembali. Semakin cepat pengembalian biaya investasi dalam suatu usaha, maka semakin baik usaha tersebut untuk dilanjutkan karena modal akan berputar dengan lancar (Zainet al., 2016).Menurut Wismaningrum et al., (2013), semakin cepat waktu payback period dibandingkan dengan periode waktu maksimum yang telah ditetapkan, maka usulan proyek usaha akan semakin layak dijalankan. Tingkat pengembalian modal dalam suatu usaha dikategorikan cepat jika nilai PP $<3$ tahun, tingkat pengembalian modal dikategorikan sedang jika nilai PP sebesar 3 tahun $<\mathrm{PP}<5$ tahun, dan dikatakan dalam kategori tingkat pengembalian lambat jika nilai $\mathrm{PP}>5$ tahun.

\section{KESIMPULAN}

Usaha penangkapan kepiting bakau oleh nelayan di Kelurahan Kandang, Kecamatan Kampung Melayu, Kota Bengkulu, masih bersifat sederhana dan tergolong usaha perikanan skala kecil (small scale fisheries). Unit penangkapan kepiting bakau terdiri dari alat penangkapan yaitu bubu lipat berukuran kecil (panjang $45 \mathrm{~cm}$, lebar $20 \mathrm{~cm}$ dan tinggi $15 \mathrm{~cm}$ ), perahu motor tempel $(0,63$ GT) dengan tenaga penggerak motor tempel jenis "ketinting" merek Honda, Nixon, Bion, Proquip dan Pujiama, yang berkekuatan 5,5-6,5 PK. Pemasangan bubu lipat adalah di perairan ekosistem hutan mangrove dengan dasar berlumpur. Lokasi pemasangan bubu lipat berjarak 2-3 km dari pemukiman nelayan, dengan waktu tempuh +1 jam. Hasil tangkapan kepiting bakau pet trip adalah $2-5 \mathrm{~kg}$.

Berdasarkan analisis kriteria investasi kelayakan usaha, kegiatan penangkapan kepiting bakau dengan menggunakan alat tangkap bubu lipat di perairan Kelurahan Kandang, Kecamatan Kampung Melayu, Kota Bengkulu adalah layak secara finansial, dan dapat untuk diteruskan.

\section{DAFTAR PUSTAKA}

Amarullah, T., Zuraidah, S., Gunawan. 2018. Kajian Pendapatan Nelayan Kepiting Bakau (Scylla serrata) di Kecamatan Samatiga Kabupaten Aceh Barat. Jurnal Perikanan Tropis. Fakultas Perikanan dan Ilmu Kelautan, Universitas Teuku Umar. Vol 5 (1) : 37-46.

[Bappeda] Badan Perencanaan, Penelitian dan Pengembangan Daerah Provinsi Bengkulu. 2017. Rencana Aksi Daerah Pengembangan Ekonomi Kemaritiman Provinsi Bengkulu Tahun 2017.

Gray, C., Simanjuntak, P., Sabur, L. K., Mapaitella, P. F. L., Varley, R. C. G. 1992. Pengantar Evaluasi Proyek. Gramedia. Jakarta. 328 hal.

Ediyanto dan Gutandjal, B. W. 2015. Analisis Rantai Pemasaran dan Pola Distribusi Kepiting Bakau (Scylla serrata) di Dobo Kabupaten Kepulauan Aru Provinsi Maluku. Jurnal Ilmiah Satya Minabahari. Fakultas IImu Kelautan dan Perikanan Universitas Satya Negara Indonesia. $49 \mathrm{hlm}$.

Irnawati, R., Susanto, A., Maesaroh, S. L. A. 2014. Waktu Penangkapan Kepiting Bakau (Scylla serrata) di Perairan Lontar Kabupaten Serang Banten. Jurnal Perikanan dan Kelautan. Jurusan Perikanan, Fakultas Pertanian Universitas Sultan Ageng Tirtayasa. Vol 4 (4) : 277282. 
Iskandar, M. D dan Ramdani, D. 2009. Analisis Hasil Tangkapan Rajungan Pada Bubu Lipat Dengan Menggunakan Jenis Umpan Yang Berbeda. Jurnal Penelitian Perikanan. Fakultas Perikanan dan IImu Kelautan Universitas Brawijaya Malang. Vol 12 (1) : 1-106.

Karima, H. R. 2013. Modifikasi Funnel Bubu Lipat Terhadap Tangkapan Lobster di Perairan Pamiripan, Teluk Palabuhan Ratu. Skripsi. Fakultas Perikanan dan IImu Kelautan, IPB.

Lastari, L. 2007. Perbandingan Hasil Tangkapan Bubu Lipat Bubu Bercelah (Escape Gap) dan Tanpa Celah (Non Escape Gap) di Perairan Kronjo. Skripsi. Departemen Pemanfaatan Sumberdaya Perikanan, FPIK, IPB.

Marliana, Y., Susanto, A., Mustahal. 2015. Tingkat Keramahan Lingkungan Bubu Lipat Yang Berbasis di Pelabuhan Perikanan Nusantara Karangantu Kota Serang Provinsi Banten. Jurnal Perikanan dan Kelautan. Jurusan Perikanan Fakultas Pertanian Universitas Sultan Ageng Tirtayasa. Serang Banten. Vol 5 (2) : 79-84.

Mufriantie, F., Feni, R., Sukardi. 2019. Analisis Usaha Penangkapan Kepiting Bakau Di Desa Pasar Ngalam Kecamatan Air Periukan Kabupaten Seluma. Prosiding Seminar Nasional Universitas Muhammdiyah Yogyakarta. Prodi Agribisnis Fakultas Pertanian Universitas Muhammadiyah Bengkulu. 418 hal.

Muldiani, D. 2007. Analisis Hasil Tangkapan Rajungan Pada Bubu Lipat Dengan Konstruksi Yang Berbeda di Perairan Kronjo, Kabupaten Tangerang. Skripsi. Fakultas Perikanan dan IImu Kelautan, IPB.

Pratama, F. A., Boesono, H., Dwi, T. 2012. Analisis Kelayakan Finansial Usaha Penangkapan Ikan Menggunakan Panah Dan Bubu Dasar Di Periran Karimunjawa. Journal of Fisheries Resources Utilization Management and Technology. Vol 1 (1) : 22-31.

Purba, R. L. 2018. Deskripsi Usaha Penangkapan Ikan Dengan Pancing Tonda di Pelabuhan Pulau Baai Kota Bengkulu. Skripsi. Program Studi Ilmu Kelautan, Universitas Bengkulu.

Rakhmadevi, C. C. 2004. Waktu Perendaman dan Periode Bulan : Pengaruhnya terhadap Kepiting Bakau Hasil Tangkapan Bubu di Muara Sungai Radak, Pontianak. Skripsi. Fakultas Perikanan dan IImu Kelautan, IPB.

Ramdani, D. 2007. Perbandingan Hasil Tangkapan Rajungan Pada Bubu Lipat Dengan Menggunakan Umpan Yang Berbeda. Skripsi. Fakultas Perikanan dan IImu Kelautan, IPB.

Rangka, N. A. 2007. Status Usaha Kepiting Bakau Ditinjau dari AspekPeluang dan Prospeknya. Balai Riset Perikanan Budidaya Air Payau. Jurnal Neptunus. Vol 14 (1) : 90-100.

Rusdi. 2010. Pengaruh Bentuk Celah Pelolosan (Escape Gap) Pada Bubu Lipat Terhadap Hasil Tangkapan Kepiting Bakau (Scylla sp.) di Desa Mayangan. Kabupaten Subang. Skripsi. Fakultas Perikanan dan IImu Kelautan, IPB.

Saebani, B. A. 2018. Studi Kelayakan Bisnis. Pustaka Setia. Bandung. 344 hal.

Saidah, S., Sofia, L. A. 2016. Pengembangan Usaha Pembesaran Kepiting Bakau (Scylla spp) Melalui Sistem Silvofishery. Jurnal Hutan Tropis. Fakultas Kehutanan, Fakultas Perikanan dan Kelautan ULM. Vol 4 (3) : 265-272.

Saraswati, Y. 2014. Analisa Pemberdayaan Masyarakat Melalui Program CSR di Wilayah Kecamatan Kampung Melayu Kota Bengkulu. Skripsi. Fakultas Ekonomi dan Bisnis, Universitas Bengkulu. 
Setiawan, P. A. K. 2006. Perbandingan Hasil Tangkapan Bubu Bambu dan Bubu Lipat di Perairan Palabuhan Ratu, Kabupaten Sukabumi, Jawa Barat. Skrispi. Fakultas Perikanan dan IImu Kelautan, IPB.

Shalichaty, S. F., Mudzakir, A. K., Rosyid, A. 2014. Analisis Teknis Dan Finansial Usaha Penangkapan Rajungan (Portunus Pelagicus) Dengan Alat Tangkap Bubu Lipat (Traps) Di Perairan Tegal. Journal of Fisheries Resources Utilization Management and Technology. Vol3 (3) : 37-43.

Sifa, N. N. 2017. Pengaruh Budaya Organisasi dan Disiplin Kerja Terhadap Kinerja Pegawai Pada Dinas Komunikasi dan Informatika Provinsi Jawa Barat. Skripsi. Fakultas Ekonomi dan Bisnis Universitas Pasundan. Bandung.

Sumali, D. H., Syaifuddin., Zain, J., Analysis Contruction Long Liner 5 GT In Countryside Bay Of Pambang Sub-Province Of Bengkalis Provinsi Riau. Journal of Fisheries Utilization Management and Technology. Vol 5 (2) : 157-158.

Tallo, I. 2015. Rancang Bangun Bubu Lipat Dalam Upaya Peningkatan Efektivitas dan Efisiensi Penangkapan Kepiting Bakau Yang Ramah Lingkungan. Disertasi. Sekolah Pascasarjana Institut Pertanian Bogor.

Tiku, M. 2004. Pengaruh Jenis Umpan dan Waktu Pengoperasian Bubu Lipat Terhadap Hasil Tangkapan Kepiting Bakau (Scylla serrata) di Kecamatan Kubu, Kabupaten Pontianak. Tesis. Bogor: Sekolah Pascasarjana, Institut Pertanian Bogor.

Tilaar, T. S. A. M. 2019. Analisis Pendapatan Nelayan Kepiting Bakau (Scylla serrata) di Kecamatan Singkil dan Kecamatan Kuala Baru. Skripsi. Fakultas Pertanian, Universitas Muhammadiyah Sumatera Utara, Medan.

Wismaningrum, K. E. P., Ismail., Fitri, A. D. P. 2013. Analisis Finansial Usaha Penangkapan One Day Fishing Dengan Alat Tangkap Multigear Di Pelabuhan Perikanan Pantai (PPP) Tawang Kabupaten Kendal.Journal of Fisheries Resources Utilization Management and Technology. Fakultas Perikanan dan IImu Kelautan Universitas Diponegoro. Vol 2 (3) : 263-272.

Zain, H. N., Triarso., Hapsari, T. D. 2016. Analisis Kelayakan Finansial Usaha Perikanan Tangkap Jaring Insang Permukaan ( Surface Gill Net) Di Pangkalan Pendaratan Ikan (PPI) Banyutowo Kabupaten Pati. Journal of Fisheries Resources Utilization Management and Technology. Fakultas Perikanan dan Ilmu Kelautan UNDIP. Vol 5 (1) : 162-169. 